\section{Lactobacillus rhamnosus and} Lactobacillus casei Affect Various Stages of Gardnerella Species Biofilm Formation

\author{
Yuanhui He, Risu Na, Xiaoxi Niu, Bingbing Xiao * and Huixia Yang * \\ Department of Obstetrics and Gynecology, Peking University First Hospital, Beijing, China
}

Bacterial vaginosis (BV) and its recurrence are most commonly associated with the formation of Gardnerella species biofilm. Probiotics are typically used to treat BV; however, the optimal period of Lactobacillus probiotic application in BV treatment remains uncertain. The present study aimed to explore the effects of Lactobacillus rhamnosus and Lactobacillus casei on various stages of biofilm formation in Gardnerella species. The biofilm-forming ability of seven strains, including one Gardnerella vaginalis ATCC 14018 and six clinically isolated Gardnerella species, was determined via gentian violet staining assay. Moreover, the sensitivity of the planktonic and biofilm forms toward metronidazole and clindamycin was assessed via microdilution broth method. L. rhamnosus Xbb-LR-1 and L. casei Xbb-LC-1 were added during various stages of biofilm formation in Gardnerella species and were cocultured for $24 \mathrm{~h}$. The biofilm thickness of each sample was determined via confocal laser scanning microscopy (CLSM). The absolute quantities of Gardnerella species in each sample was obtained via real time polymerase chain reaction method, and the $\mathrm{pH}$ value was obtained using a $\mathrm{pH}$ indicator paper. Biofilm formation by Gardnerella species in a medium with distinct pH values was observed via gentian violet staining, CLSM, and scanning electron microscopy (SEM). The biofilm increased the resistance of Gardnerella species toward metronidazole and clindamycin. L. rhamnosus added at the initial biofilm formation stage in Gardnerella species exhibited highest inhibitory effect, with a percentage inhibition of $38.17 \% \pm$ $1.35 \%$. When the $\mathrm{pH}$ value of the culture medium was $<4.5$ or $>6.5$, ATCC 14018 could hardly form a biofilm; however, at $\mathrm{pH} \geq 4.5$ and $\leq 6.5$, it was able to form a stronger biofilm. The amount of biofilm attained maximum value at optical density of $3.29 \pm 0.28$ (595 nm), $\mathrm{pH}$ 5.5, and at 36 h. Biofilm formation increases the resistance of Gardnerella species toward antibiotics. Maintaining an acidic vaginal environment with $\mathrm{pH}<4.5$ and a vaginal microbiota dominated by Lactobacillus remarkably prevents the formation of Gardnerella species biofilm at the initial stage, which further has a significant impact on the treatment and prevention of biofilm-related infections.

Keywords: Lactobacillus rhamnosus, Lactobacillus casei, biofilm formation, bacterial vaginosis, Gardnerella species 


\section{INTRODUCTION}

Bacterial vaginosis (BV) is one of the most common lower genital tract infections found in women of reproductive age (Verstraelen and Swidsinski, 2019). It affects millions of women worldwide each year and is associated with infertility (Moragianni et al., 2019), ectopic pregnancy (Rajalakshmi and Kalaivani, 2016), sexually transmitted diseases (Abbai et al., 2016), adverse pregnancy outcomes (Subtil et al., 2018), and a higher risk of reproductive tract infections (Moragianni et al., 2019; Saweri et al., 2019). Patients with BV often present vaginal itching, increased vaginal secretions, pain, and odor (Rosca et al., 2020). The high rate of treatment failure and recurrence of BV might increase the risk of acquiring human papillomavirus (King et al., 2011) and human immunodeficiency virus (Haddad et al., 2018). BV has an adverse impact on women's mental and physical health (Danielsson et al., 2011) and often leads to a high global burden and cost (Peebles et al., 2019).

Biofilm is a membrane-like structure comprising polysaccharide matrix, vitamins, and other components; biofilms surround a microorganism and are often characterized by a complex internal structure and channels containing nutrient cycles (Hardy et al., 2017). Biofilms play a pivotal role in BV (Swidsinski et al., 2005; Swidsinski et al., 2008; Swidsinski et al., 2010; Swidsinski et al., 2011; Javed et al., 2019; Verstraelen and Swidsinski, 2019), and can be recovered on the vaginal mucosa of BV patients after stopping the intake of antibiotics (Swidsinski et al., 2008).

Gardnerella species are one of the most virulent BV-related pathogens (Alves et al., 2014), and their initial adhesion initiates biofilm formation, which is considered a crucial step in biofilm formation (Castro et al., 2019) and the development of BV (Rosca et al., 2020). The failure of antibiotic treatment for BV patients may be due to the high population of Gardnerella species in the biofilm (Verwijs et al., 2020). Therefore, the present study aimed to demonstrate the adverse impact on antimicrobial resistance by biofilm formation.

Healthy vaginal microbes are generally dominated by lactic acid-producing Lactobacillus species, which create and sustain an acidic $\mathrm{pH}$ that inhibits the growth and adhesion of $\mathrm{BV}$-associated pathogens (Rosca et al., 2020); however, BV is often characterized by a higher vaginal $\mathrm{pH}$ and the absence of lactobacilli (Reznichenko et al., 2020; Rosca et al., 2020). Several studies have demonstrated that lactobacilli can reduce the risk of BV and its recurrence (Xiao et al., 2016; Reznichenko et al., 2020). Numerous studies have revealed the effects of lactobacilli on biofilm formation of pathogens such as Candida albicans (Rossoni et al., 2018; Tan et al., 2018), Staphylococcus aureus (Merghni et al., 2017), and Streptococcus mutans (Keller et al., 2011).

Studies on the antagonizing effect of Lactobacillus species on Gardnerella species have mostly focused on changes in the population of Gardnerella species (Machado et al., 2013; Breshears et al., 2015) rather than directly observing their effect on the biofilms. Lactobacillus rhamnosus and Lactobacillus casei are commensal ingredients in probiotic drugs, which are commonly used in the BV treatment. These two Lactobacillus species colonized in the normal vaginal microbiota, which has a positive preventive effect in reducing the recurrence of BV (Xiao et al., 2019); this presumably occurs via mechanisms such as inhibition of Gardnerella species biofilms; however, the optimal application period of Lactobacillus probiotics in the treatment of $\mathrm{BV}$ remains uncertain. Therefore, we selected these two clinical isolates to explore their effects on various stages of biofilm formation in Gardnerella species.

\section{MATERIALS AND METHODS}

\section{Collection of Patients Specimens and Ethical Approval}

The strains in our study included Gardnerella species ATCC14018, which has been identified as G. vaginalis (Vaneechoutte et al., 2019), six clinically isolated Gardnerella species strains (XB-01-XB-06), one L. rhamnosus strain Xbb-LR1 , and one L. casei strain Xbb-LC-1. Six strains of Gardnerella species were isolated from patients with BV between January and February 2020. The BV patients initially visited the Obstetrics and Gynecology Clinic of Peking University First Hospital and did not use antibiotics for a week prior to their visit. They were diagnosed through Nugent score and clinical symptoms and did not suffer from other urogenital tract infectious diseases. $L$. rhamnosus strain Xbb-LR-1 and L. casei strain Xbb-LC-1 were isolated from healthy volunteers ( $>18$ years old) at the health checkup clinic of the hospital between October and December 2019. These women did not suffer from any urogenital tract infections, had no sexual intercourse 1 week before admission, and did not use any antibiotics within 3 months of admission. All the samples were transported to the Microecology laboratory of the hospital and inoculated within $2 \mathrm{~h}$ after collection, and their corresponding clinical information was recorded. The Ethics Committee of Peking University First Hospital approved this study (V2.0/201504.20), and written informed consent was obtained from all the participants.

\section{Isolation, Identification, and Recovery of Bacteria}

The culture was screened by streaking a vaginal swab in Casman blood agar medium with $5 \%(\mathrm{w} / \mathrm{v})$ defibrinated rabbit blood, followed by trilinear method and further incubated at $37^{\circ} \mathrm{C}$ under anaerobic condition (5\% CO2, 95\% nitrogen) for 48-72 h (Bohr et al., 2020). Suspicious colonies were transferred to blood agar medium for $48-72 \mathrm{~h}$ for purification culture using the Gram's method and observed under an optical microscope with oil immersion lens (Leica Microsystems, Mannheim, Germany). Gardnerella species revealed uniform morphology of short rodshaped bacteria, whereas Lactobacillus presented a uniform morphology of gram-positive, large rod-shaped bacteria. After several purification cultures, the DNA from a single colony was extracted using the QIAamp DNA Mini Kit (QIAGEN, Germany), as previously described (He et al., 2020b). Briefly, the bacterial suspension was made from the sample using 
supplemented brain-heart infusion (sBHI) medium. SBHI comprised 9.25\% (wt/v) BHI (Liofilchem), 0.3\% (wt/v) glucose (Liofilchem), and $0.3 \%(\mathrm{w} / \mathrm{v})$ soluble starch (Thermo Fisher Scientific, Lenexa, KS, USA). Thereafter, the samples were centrifuged at $10,000 \mathrm{rpm}(\sim 11,500 \times \mathrm{g})$ for $1 \mathrm{~min}$. The supernatant was discarded and liquid Amies buffer GA was mixed. The proteinase $\mathrm{K}$ and the liquid Amies buffer GB were subsequently added to the suspension and incubated at $70^{\circ} \mathrm{C}$ for $10 \mathrm{~min}$. Subsequently, 100\% ethanol (w/v) was added followed by centrifugation. DNA was then isolated following a series of centrifugations with TIANGEN spin columns and buffer solutions. Next, DNA was eluted in $100 \mu$ l elution buffer (TE Buffer). Its quantity and quality were assessed at absorbances of $260 \mathrm{~nm}$ and at A260/280 nm via a Spectrophotometer (Nano Drop One, Thermo Fisher). Furthermore, the samples were stored at $-20^{\circ} \mathrm{C}$. To identify the isolates, the $16 \mathrm{~S} \mathrm{rDNA}$ sequences primers 27F (5'-AGAGTTTGATCCTGGCTCAG$\left.3^{\prime}\right)$ and 1492R (5'-GGTTACCTTGTTAGACTT-3') were used (Chervinets et al., 2018). The isolates were confirmed by comparing the $16 \mathrm{~S}$ rDNA sequences with the GenBank library using the BLAST program (https://blast.ncbi.nlm.nih.gov).

The clinically isolated Gardnerella species could not be identified at the species level by $16 \mathrm{~S}$ rDNA sequencing, and hence, they were collectively named as Gardnerella species (Vaneechoutte et al., 2019). The strains were stored at $-80^{\circ} \mathrm{C}$ in Microbank microbial storage tubes (PL.170/M, PRO-LAB, Canada). Every strain to be tested was recovered and purified before the experiment to ensure bacterial viability and purity. The viability of bacteria was determined by the growth and presence of bacterial colonies, whereas the purity was evaluated based on the morphology of the colony and bacteria under the oil microscope. Gardnerella species were grown in Casman blood agar medium with 5\% (w/v) defibrinated rabbit blood, whereas Lactobacillus was cultivated on de Man, Rogosa, and Sharpe (MRS) broth agar (HaiBo, Qingdao, China) at $37^{\circ} \mathrm{C}$ under anaerobic conditions.

\section{Selection of the Most Suitable Medium for Gardnerella Species Biofilm Formation}

A single colony of ATCC 14018 was picked from the Casman blood agar medium to adjust the bacterial suspension to 0.5 McFarland using a nephelometer (Biomerieux, France) with a concentration of $10^{8} \mathrm{CFU} / \mathrm{ml}(\mathrm{OD} 590=0.5)$ (Turovskiy et al., 2012) in ATCC medium 1685 (M1486-02, ELITE-MEDIA, USA) and supplemented brain-heart infusion broth (sBHI) (AOBOX, Beijing, China). ATCC medium 1685 comprised 0.4\% (wt/v) 4(2-hydroxyethyl)-1-piperazineethanesulfonic acid (HEPES) (Liofilchem), 1.5\% (wt/v) Proteose Peptone No.3 (Liofilchem), $0.5 \%(\mathrm{w} / \mathrm{v}) \mathrm{NaCl}$ (Liofilchem), $0.5 \%(\mathrm{w} / \mathrm{v})$ glucose (Liofilchem).The two culture media were used to dilute the bacterial suspension to $10^{6} \mathrm{CFU} / \mathrm{ml}$. Two bacteria-free media served as their respective control groups; $200 \mu$ l suspension of ATCC14018 was inoculated in each well of a 96-well plate (Falcon, Corning Inc., Corning, NY). Under atmospheric conditions of $101.325 \mathrm{kPa}$, the media were diluted and further inoculated with the sample within $15 \mathrm{~min}$. The biofilm formation was assessed by gentian violet staining assay (as described below) after incubation at $37^{\circ} \mathrm{C}$ under anaerobic conditions (Bohr et al., 2020) without agitation for $48 \mathrm{~h}$.

\section{Quantification of Biofilm Formation by Gentian Violet Staining Assay}

To quantitatively measure biofilm formation, a gentian violet staining assay was performed, as previously described (Harwich et al., 2010; Patterson et al., 2010; Castro et al., 2015) with some adjustments. Planktonic bacteria were eliminated from the wells by removing the spent medium and washing the wells with 300 $\mu \mathrm{l}$ of $1 \times$ phosphate buffer saline (PBS) (BL302A, Biosharp, China). The biofilm and bacteria adhered to the wells were retained on the wells. The wells were air-dried for $60 \mathrm{~min}$, and the biofilms were stained with $200 \mu \mathrm{l} 0.4 \%$ (w/v) gentian violet stain (G1070, Solarbio, Beijing, China) for $30 \mathrm{~min}$. Thereafter, the wells were washed gently with $200 \mu \mathrm{l}$ PBS to remove the excess stain and then air-dried for $5 \mathrm{~min}$. The gentian violet was solubilized with $200 \mu \mathrm{l} 33 \%(\mathrm{v} / \mathrm{v})$ acetic acid per well. For quantitative results, the absorbance of gentian violet at a wavelength of $595 \mathrm{~nm}$ using an Epoch microplate spectrophotometer was determined (BioTek Instruments, Winooski, VT, USA) at $25^{\circ} \mathrm{C}$. The growth of ATCC 14018 biofilm in different situations was categorized according to the OD. OD cut-off value (ODc) was defined as three standard deviations (SD) above the mean OD of the negative control: ODc $=$ average $\mathrm{OD}$ of negative control $+(3 \times \mathrm{SD}$ of negative control), $\mathrm{OD} \leq \mathrm{ODc}=$ nonbiofilm producer; $\mathrm{ODc}<\mathrm{OD} \leq 2 \times \mathrm{ODc}=$ weak biofilm producer; $2 \times \mathrm{ODc}<\mathrm{OD} \leq 4 \times \mathrm{ODc}=$ moderate biofilm producer; $4 \times$ ODc $<$ OD $=$ strong biofilm producer (Stepanovic et al., 2000; Stepanovic et al., 2007). The biofilm formation ability of the six clinically isolated Gardnerella species strains and the ATCC14018 strain was determined via gentian violet staining assay. All analyses were performed thrice over 3 days, with each sample in quintuplicate for technical replicates, and the results are presented as the mean \pm standard deviation (SD).

\section{Biofilm Formation of Gardnerella Species at 24 and $48 \mathrm{~h}$}

SBHI was used in the subsequent steps as it is more beneficial for biofilm formation. A single colony was picked from the solid medium to adjust the bacterial suspension concentration to $10^{8}$ $\mathrm{CFU} / \mathrm{ml}$ (OD $590 \mathrm{~nm}=0.5$ ) in sBHI (Turovskiy et al., 2012). The clinically isolated bacteria and the ATCC14018 strain were diluted to $10^{6} \mathrm{CFU} / \mathrm{ml}$ and then inoculated in 96-well plates (with $200 \mu \mathrm{l}$ per well). Inoculation was completed within $15 \mathrm{~min}$, and the strains were cultured in an anaerobic environment for 24 and $48 \mathrm{~h}$, respectively. Each sample was assessed in quintuplicate for technical replicates in each assay and in three different assays for biological replicates.

\section{Observing Biofilm Formation via Confocal Laser Scanning Microscopy}

CLSM was used to observe the biofilm formation of Gardnerella species before and after Lactobacillus interference and in a medium with different $\mathrm{pH}$ values. Biofilm staining was 
performed according to the manufacturer's instructions mentioned on the Filmtracer Live/Dead biofilm viability kit (L10316, Thermo Fisher Scientific, USA) with some adjustments. Briefly, the samples were cultured in 24-well plates (Falcon, Corning Inc., Corning, NY) with a $14 \mathrm{~mm} \times 14$ mm circular cover glass (MutoPure Chemicals Co. Ltd) at the bottom of each well at $37^{\circ} \mathrm{C}$ under anaerobic conditions. The coverslip was removed after their incubation, washed thrice with sBHI, and then incubated for 25 min with $300 \mu \mathrm{l}$ of fluorescent stain in the dark at $25^{\circ} \mathrm{C}$. The stain solution was prepared with 3 $\mu \mathrm{l}$ of propidium iodide stain and $3 \mu \mathrm{l}$ of $\mathrm{SYTO}^{\circledR} 9$ stain to $1 \mathrm{ml}$ of sBHI. Thereafter, the samples were washed gently with sBHI thrice after incubation in the stain solution to remove the excess stain. The reactor coupon was placed upside down in a $20 \times$ $20 \mathrm{~mm}$ dish and the dish was filled with approximately $1000 \mu \mathrm{l}$ sBHI to cover the coupon surface by $2 \mathrm{~mm}$, followed by observation on CLSM (LSM510, Carl Zeiss, Thornwood, NY) by an oil lens at $63 \times$ magnification combined with 0.75 zoom. Spectral Borealis lasers (green, $488 \mathrm{~nm}$; red, $561 \mathrm{~nm}$ ) were used for excitation. Each sample was manipulated for similar time periods. The images were obtained with a resolution of 246.03 $\mu \mathrm{m} \times 246.03 \mu \mathrm{m}$ image size. The tomographic scan was performed at intervals of $1 \mu \mathrm{m}$ in the $\mathrm{Z}$-axis direction to obtain a series of images of each layer, and the threedimensional images were combined using OLYMPUSFLuoView.Ver.1.6b software. The biofilm thickness of each sample was recorded, and each sample was evaluated in five fields (Beaudoin et al., 2017).

\section{Observation of Biofilm Formation of Gardnerella Species by Scanning Electron Microscopy}

SEM was used to observe the formation of Gardnerella species biofilms in a medium at different $\mathrm{pH}$ values. The ATCC14018 suspension was adjusted to a final concentration of $10^{6} \mathrm{CFU} / \mathrm{ml}$ in sBHI at different $\mathrm{pH}$ values. The samples were cultured in 24well plates with a $14 \times 14 \mathrm{~mm}$ circular cover glass at the bottom of each well at $37^{\circ} \mathrm{C}$ under anaerobic conditions without agitation for $48 \mathrm{~h}$. The sBHI in each well was removed lightly, and the samples in the well were then washed once with $300 \mu 1 \times$ PBS. The planktonic bacteria of each sample were removed and the adhered biofilm was left in the wells. The samples were fixed with $3 \%$ glutaraldehyde at $4^{\circ} \mathrm{C}$ overnight, dehydrated using an ethanol series, and substituted with t-butyl alcohol for freeze-drying (JFD-320, JEOL, Japan). The dried specimen was coated with platinum using an auto fine coater (JFC-3000EC, JEOL, Japan) and observed using SEM (JSM- 7900F, JEOL, Japan) at $3 \mathrm{kV}$ (Thellin et al., 2016; Jung et al., 2019).

\section{Minimum Inhibitory Concentration and Minimal Biofilm Inhibitory Concentration of Gardnerella Species Toward Metronidazole and Clindamycin}

MIC and MBIC of six Gardnerella species strains and the ATCC14018 strain toward metronidazole and clindamycin was determined via microdilution broth method according to the
CLSI guideline (Wayne, PA, USA, 2018). The final concentrations of metronidazole and clindamycin (1442009 and 100037, National Institutes for Food and Drug Control, China) applied to the planktonic bacteria were $0.125-128 \mathrm{mg} / \mathrm{L}$ and $0.0625-64 \mathrm{mg} / \mathrm{L}$, respectively. The final concentrations of metronidazole and clindamycin applied to the biofilm form were $0.25-256 \mathrm{mg} / \mathrm{L}$ and $0.125-128 \mathrm{mg} / \mathrm{L}$, respectively. Bacteroides fragilis ATCC 25285 was used as a quality control.

After culturing the Gardnerella species on blood plates under anaerobic conditions for 48-72 h, single colonies were picked from Casman blood agar medium to adjust the bacterial suspension concentration to $10^{8} \mathrm{CFU} / \mathrm{ml}$ (OD $590=0.5$ ) (Turovskiy et al., 2012) in sBHI. The suspension $(100 \mu \mathrm{l}, 2 \times$ $10^{6} \mathrm{CFU} / \mathrm{ml}$ ) was mixed with different concentrations of drugs at 1:1 volume ratio, and the mixture was inoculated in 96-well plates and cultured for $48-72 \mathrm{~h}$. The modulation and inoculation processes were completed within $15 \mathrm{~min}$. The sensitivity of both antibiotics was classified as follows: clindamycin (sensitive: $\mathrm{MIC} \leq 2 \mathrm{mg} / \mathrm{L}$; intermediate: $\mathrm{MIC}=4 \mathrm{mg} / \mathrm{L}$; resistance: $\mathrm{MIC} \geq$ $8 \mathrm{mg} / \mathrm{L}$ ), metronidazole (sensitive: $\mathrm{MIC} \leq 8 \mathrm{mg} / \mathrm{L}$; intermediate: $\mathrm{MIC}=16 \mathrm{mg} / \mathrm{L}$, resistance: $\mathrm{MIC} \geq 32 \mathrm{mg} / \mathrm{L})$. The breakpoints were obtained according to CLSI guideline (Wayne, PA, USA, 2018).

Briefly, $200 \mu \mathrm{l}$ of each Gardnerella species suspension at a concentration of $1 \times 10^{6} \mathrm{CFU} / \mathrm{ml}$ in sBHI was incubated in 96well microplates at $37^{\circ} \mathrm{C}$ under anaerobic conditions without agitation for 24 and $48 \mathrm{~h}$. The sBHI was removed and washed once with PBS, and the non-adherent bacteria were removed. Series of two-fold dilutions of metronidazole $(0.25-256 \mathrm{mg} / \mathrm{L})$ and clindamycin $(0.125-128 \mathrm{mg} / \mathrm{L})$ were added. After the addition of antibiotics, the biofilm was cultured under anaerobic conditions for $48 \mathrm{~h}$, and MBIC was observed as previously described (Peeters et al., 2008). SBHI medium with each bacterial suspension in a 96-well plate without antibiotics was used as a growth control for each strain.

\section{Effects of Lactobacillus on Different Stages of Biofilm Formation of Gardnerella Species}

The suspensions of ATCC14018, L. rhamnosus Xbb-LR-1, and L. casei Xbb-LC- 1 with an adjusted concentration of $10^{6} \mathrm{CFU} / \mathrm{ml}$ were used in the following groups and incubated at $37^{\circ} \mathrm{C}$ under anaerobic conditions without agitation in 24 well plates. A $14 \times 14 \mathrm{~mm}$ circular cover glass was placed at the bottom of each well.

As shown in Supplementary Figure 1. We divided the samples into three groups according to the processing procedure. Group one (in the competition assays): The control group (sample A) was a $300 \mu \mathrm{l}$ suspension of Gardnerella species cultured for $24 \mathrm{~h}$. Next, $150 \mu \mathrm{l}$ suspension of Lactobacillus and $150 \mu \mathrm{l}$ of Gardnerella species were mixed and cultured for $24 \mathrm{~h}$ (sample B and C). Group two (in the interference assays): The control group involved culturing of $150 \mu \mathrm{l}$ of Gardnerella species suspension alone in one well for $24 \mathrm{~h}$, followed by the addition of $150 \mu \mathrm{l}$ of sBHI to the same well and culturing for $24 \mathrm{~h}$ (sample D). Thereafter, $150 \mu \mathrm{l}$ suspension of Gardnerella species was added to the well and cultured for $24 \mathrm{~h}$. Next, $150 \mu \mathrm{l}$ of the 
Lactobacillus suspension was mixed and cocultured for another $24 \mathrm{~h}$ (sample E and F). Group three (in the interference assays): The control group involved culturing $150 \mu \mathrm{l}$ of Gardnerella species suspension alone for $48 \mathrm{~h}$, followed by the addition of $150 \mu \mathrm{l}$ of sBHI and culturing for $24 \mathrm{~h}$ (sample G). Next, $150 \mu \mathrm{l}$ suspension of Gardnerella species was cultured alone for $48 \mathrm{~h}$, followed by the addition of $150 \mu$ of Lactobacillus suspension and coculturing for another $24 \mathrm{~h}$ (sample $\mathrm{H}$ and I).

The biofilm thickness of the samples was examined by CLSM. The absolute quantities of Gardnerella species of the samples was performed via real-time PCR method as described below. Their $\mathrm{pH}$ values were tested by $\mathrm{pH}$ test paper (Jianjun, China). The last $\mathrm{pH}$ value was determined in the first $15 \mathrm{~s}$ after the bacterial suspension made contact with the test paper, and the results were confirmed at least thrice.

\section{Real-Time-PCR for Absolute Quantification of Gardnerella Species in Different Samples}

Approximately $2 \mathrm{ml}$ Gardnerella species suspension was used to extract DNA as before mentioned after it was adjusted to a concentration of $10^{8} \mathrm{CFU} / \mathrm{ml}$ in $\mathrm{sBHI}$. The DNA was dissolved in a $100 \mu \mathrm{l}$ TE solution. The original DNA concentration was set as $10^{8}$ copies $/ \mathrm{ml}$. After 10 folds serial dilution, seven DNA concentrations of $10^{8}-10^{2}$ copies/ml were obtained, respectively. $\mathrm{DdH} 2 \mathrm{O}$ was selected as a blank control. Real time PCR was performed with a reaction volume of $20 \mu \mathrm{l}$ containing SYBR Green PCR Master Mix (Toyobo, Osaka, Japan), $25 \mathrm{nM}$ of the primers, and $1 \mu \mathrm{l}$ of DNA extracted from each concentration. Gv-F/R was used as primers for the specificity reference genes of Gardnerella species. The specificity of the primers (GV-F/R: $5^{\prime}-$ C CG A A T T T G C G A T T T C T T C T - 3'/ 5' - CG T A C GG AAGTTTTGGAAGC-3') (Castro et al., 2019) used in this study was confirmed by polymerase chain reaction (PCR) as previously described (Byun et al., 2004). The reaction conditions were as follows: $95^{\circ} \mathrm{C}$ for $60 \mathrm{~s}$, followed by 40 cycles of $95^{\circ} \mathrm{C}$ for $15 \mathrm{~s}, 60^{\circ} \mathrm{C}$ for $15 \mathrm{~s}$, and $72^{\circ} \mathrm{C}$ for $45 \mathrm{~s}$ (Byun et al., 2004). Each concentration was conducted in triplicate for technical replicates in each assay and in two assays. Ct values obtained at each concentration are expressed as the mean $\pm \mathrm{SD}$; a standard regression curve (concentration-CT value) was established ( $\mathrm{Lv}$ et al., 2019). DNA was isolated from the samples of Group A, B and $\mathrm{C}$, following exanimated via real-time PCR method. DdH2O was selected as a blank control and the DNA extracted from $L$. rhamnosus, and L. casei were selected as negative control. Each sample was tested in triplicate, and the mean values were calculated. The average DNA concentration (copies $/ \mathrm{ml}$ ) of each sample was then obtained and are presented as the mean $\pm \mathrm{SD}$.

\section{Effects of Different pH on the Biofilm Formation of Gardnerella Species}

The $\mathrm{pH}$ of sBHI was adjusted to $3.5,4.0,4.5,5.0,5.5,6.0,6.5,7.0$, and 7.5. The ATCC14018 strain was used in this step. $\mathrm{NaOH}$ solution $(10 \mathrm{~mol} / \mathrm{L})$ was prepared from $\mathrm{NaOH}$ particles (Thermo Fisher Scientific, USA) under aseptic conditions, followed by autoclave sterilization. Subsequently, $10 \mathrm{moL} / \mathrm{L} \mathrm{NaOH}$ solution and $36.5 \%-38.0 \%$ concentrated hydrochloric acid (H1758 MSDS, Sigma-Aldrich) were used for adjusting sBHI to different $\mathrm{pH}$ values.

The $\mathrm{pH}$ value of sBHI was 6.5 as evaluated by the $\mathrm{pH}$ test paper test. Considering the $\mathrm{pH}$ value of $\mathrm{sBHI}$ as the initial $\mathrm{pH}$ value (6.5), approximately $10 \mu \mathrm{l}$ of concentrated hydrochloric acid was added for every 0.5 reduction in $\mathrm{pH}$ value, and 5-10 $\mu \mathrm{l}$ of $10 \mathrm{moL} / \mathrm{L} \mathrm{NaOH}$ solution was added for every 0.5 increase in $\mathrm{pH}$ value.

Gardnerella species suspension was adjusted to a concentration of $1 \times 10^{6} \mathrm{CFU} / \mathrm{ml}$ by the corresponding medium at different $\mathrm{pH}$ values. Furthermore, the bacterial solution $(150 \mu \mathrm{l})$ in each $\mathrm{pH}$ medium was mixed with $150 \mu \mathrm{l}$ of sBHI at the corresponding $\mathrm{pH}$ value.

The resulting solution was added to the 96-well microplate and coincubated at $37^{\circ} \mathrm{C}$ under anaerobic condition without agitation. Their biofilms were quantified with gentian violet staining at $12 \mathrm{~h}, 24 \mathrm{~h}, 36 \mathrm{~h}, 48 \mathrm{~h}, 60 \mathrm{~h}$, and $72 \mathrm{~h}$ during culture. The sBHI solution without bacterial suspension at $12 \mathrm{~h}, 24 \mathrm{~h}, 36 \mathrm{~h}, 48 \mathrm{~h}, 60 \mathrm{~h}$, and $72 \mathrm{~h}$ was set as the corresponding blank control. This experiment was repeated thrice in five copies.

A $150 \mu \mathrm{l}$ suspension at a concentration of $1 \times 10^{6} \mathrm{CFU} / \mathrm{ml}$ of Gardnerella species was mixed with $150 \mu \mathrm{l}$ sBHI at the corresponding $\mathrm{pH}$ value. Thereafter, the samples were incubated for $48 \mathrm{~h}$ in anaerobic wells in a 24-well plate with circular cover glass. Biofilm formation was observed by CLSM and SEM.

\section{Statistical Analysis}

SPSS 20.0 was used as the statistical software. A paired-samples ttest was used to analyze the effect of Gardnerella species biofilm formation on the susceptibility of bacteria to antibiotics. Spearman analysis was used to analyze the linear correlation between the biofilm formation of Gardnerella species and the MICs of metronidazole and clindamycin against the planktonic and biofilm forms of the bacteria. An independent sample T test was used to analyze the difference in biofilm thickness of Gardnerella species after interference by different Lactobacillus groups. One-way ANOVA was performed to analyze the differences in biofilm thickness among the three groups. Nonparametric Wilcoxon test was used to analyze the statistical significance in the percentage of biofilms inhibited by lactobacilli added at three different periods. Variance analysis of repeated measurements was used to observe whether a significant difference was present in the amount of biofilm formation of ATCC14018 at different $\mathrm{pH}$ values. A $p$ value < 0.05 indicated statistical significance.

\section{RESULTS AND DISCUSSION}

\section{Collection of the Bacteria}

Six Gardnerella species strains were isolated from 15 BV patients. Their mean age, mean $\mathrm{pH}$ value, and mean Nugent score were 
$38.50 \pm 2.06$ years, $4.86 \pm 0.39$, and $8 \pm 0$, respectively. More details about their clinical information are summarized in Supplementary Table 1.

\section{Medium Selected for Gardnerella Species Biofilm Formation}

Both media were beneficial for Gardnerella species biofilm formation $(p=0.000)$ in vitro. At $48 \mathrm{~h}$, the ability of Gardnerella species to form biofilms in sBHI and ATCC media at OD $595 \mathrm{~nm}$ were $2.41 \pm 0.12$ and $1.73 \pm 0.29$, respectively. The OD $595 \mathrm{~nm}$ of the control groups of the two media were $0.40 \pm$ 0.07 and $0.42 \pm 0.09$, respectively. Their difference was significant $(p=0.000)$. The biofilm-forming ability of Gardnerella species in sBHI was stronger than that of ATCC medium. Therefore, the sBHI medium was selected as the culture medium for Gardnerella species in subsequent experiments.

\section{Biofilm Formation Increases Gardnerella Species Resistance to Antibiotics}

As summarized in Table 1, the MIC ranges of metronidazole and clindamycin against Bacteroides fragilis ATCC 25285 were $0.25-$ $1 \mathrm{mg} / \mathrm{L}$ and $0.5-2 \mathrm{mg} / \mathrm{L}$, respectively, which indicate that the experimental conditions are satisfactory and the results are credible.

The biofilm acts as a barrier and protects the enclosed bacterial cells against the principal antibiotic therapy, which often results in treatment failure and persistent infection (Verstraelen and Swidsinski, 2019; Rosca et al., 2020). The biofilm formation is divided into several stages of bacterial aggregation, maturation, and dispersion (Muzny et al., 2019). It has been demonstrated that the biofilm can increases the resistance of Gardnerella species to both metronidazole and clindamycin. The biofilm formation capacity at $48 \mathrm{~h}$ positively correlated with both ratios of $\mathrm{MBIC} / \mathrm{MIC}$ in metronidazole (correlation coefficient $=0.601, p=0.018$ ) and the ratio of $\mathrm{MBIC} / \mathrm{MIC}$ in clindamycin (correlation coefficient $=0.318, p=$ 0.000 ) at $48 \mathrm{~h}$. The biofilm formation capacity at $24 \mathrm{~h}$ positively correlated with the ratio of MBIC/MIC in clindamycin at $24 \mathrm{~h}$ (correlation coefficient $=0.949, p=0.000$ ). No correlation was observed between the biofilm formation capacity at $24 \mathrm{~h}$ and the ratio of $\mathrm{MBIC} / \mathrm{MIC}$ in metronidazole at $24 \mathrm{~h}$ (correlation coefficient $=0.350, p>0.05)$. However, numerous strains are required for further validation. Moreover, none of the official agencies, that is, EUCAST or CLSI, have set up standardized definitions of biofilm endpoint parameters (Thieme et al., 2019). Changes in drug sensitivity after the formation of biofilms in the present study were determined by fold point changes observed via gentian violet staining assay (Peeters et al., 2008), and more rigorous judgment methods will be adopted in subsequent studies.

Biofilm formation increased the antibiotic resistance of Gardnerella species presumably through the following mechanisms. (1) The bacteria in the biofilm core consumed the oxygen and nutrients, which slowed down the growth and metabolism of bacteria in the inner stratum of the biofilm. When exposed to antibiotics, the bacteria acquired increased tolerance, with reduced susceptibility and without undergoing genetic changes (Prax and Bertram, 2014). (2) Relatively large antibiotic compounds were restricted by the matrix, which slowed down penetration through the biofilm (Cerca et al., 2005; Jefferson et al., 2005). (3) The matrix components neutralized the effects of the antibiotics (Fux et al., 2005). (4) The applied antibiotics were degraded by live bacteria after they were pumped out of the biofilm (Van Acker et al., 2014). Due to these mechanisms, the biofilm-associated infections generally manifest as persistent chronic progressive infections and are characterized by relapses.

The treatment of biofilm-related diseases with antibiotics is associated with several challenges. New treatment programs are constantly being explored, and the use of probiotics to restore the vaginal environment is one of the present BV treatment programs (Kim et al., 2019; Reznichenko et al., 2020; Yang et al., 2020). Biofilm formation generally includes four stages: adhesion, microcolony formation and coaggregation, maturation, and dispersion (Muzny et al., 2019). Therefore, the treatment direction should not focus solely on formed biofilms but also on different growth stages of biofilms (Lamret et al., 2020). Therefore, this study attempted to use two different clinically isolated Lactobacillus species (Xbb-LR-1 and Xbb-LC-

TABLE 1 | Gardnerella species biofilm formation and minimum inhibitory concentration (MIC) of metronidazole and clindamycin against the planktonic and biofilm forms.

\begin{tabular}{|c|c|c|c|c|c|c|c|c|}
\hline \multirow[t]{2}{*}{ Strains } & \multirow{2}{*}{$\begin{array}{c}\text { Biofilm formation } \\
\text { at } 24 \mathrm{~h}\end{array}$} & \multirow{2}{*}{$\begin{array}{l}\text { Biofilm formation } \\
\text { at } 48 \mathrm{~h}\end{array}$} & \multicolumn{3}{|c|}{ Metronidazole } & \multicolumn{3}{|c|}{ Clindamycin } \\
\hline & & & $\begin{array}{c}\text { MIC } \\
(\mathrm{mg} / \mathrm{L})\end{array}$ & $\begin{array}{l}\text { Ratio of MBIC/ } \\
\text { MICat } 24 \text { h }\end{array}$ & $\begin{array}{l}\text { Ratio of MBIC/ } \\
\text { MICat } 48 \mathrm{~h}\end{array}$ & $\begin{array}{c}\text { MIC } \\
(\mathrm{mg} / \mathrm{L})\end{array}$ & $\begin{array}{l}\text { Ratio of MBIC/ } \\
\text { MICat } 24 \mathrm{~h}\end{array}$ & $\begin{array}{c}\text { Ratio of MBIC/ } \\
\text { MICat } 48 \mathrm{~h}\end{array}$ \\
\hline XB-06 & $0.39 \pm 0.03(\mathrm{~N})$ & $1.65 \pm 0.17(\mathrm{M})$ & 128 & $2(256 / 128)$ & $2(256 / 128)$ & 0.0625 & $2(0.125 / 0.0625)$ & $2048(128 / 0.0625)$ \\
\hline XB-05 & $0.34 \pm 0.04(\mathrm{~N})$ & $1.73 \pm 0.18(\mathrm{M})$ & 1 & $4(4 / 1)$ & $16(16 / 1)$ & 0.0625 & $2(0.125 / 0.0625)$ & $2(0.125 / 0.0625)$ \\
\hline XB-04 & $0.61 \pm 0.07(\mathrm{~W})$ & $3.23 \pm 0.61(S)$ & 16 & $8(128 / 16)$ & $16(256 / 16)$ & 0.0625 & $4(0.25 / 0.0625)$ & $2048(128 / 0.0625)$ \\
\hline XB-03 & $0.35 \pm 0.04(\mathrm{~N})$ & $1.81 \pm 0.33(\mathrm{M})$ & 0.125 & $8(2 / 0.125)$ & $8(2 / 0.125)$ & 0.0625 & $2(0.125 / 0.0625)$ & $2(0.125 / 0.0625)$ \\
\hline XB-02 & $0.34 \pm 0.03(\mathrm{~N})$ & $2.20 \pm 0.60(\mathrm{M})$ & 0.125 & $1(0.125 / 0.125)$ & $8(1 / 0.125)$ & 0.0625 & $2(0.125 / 0.0625)$ & $2(0.125 / 0.0625)$ \\
\hline XB-01 & $0.37 \pm 0.03(\mathrm{~N})$ & $2.50 \pm 0.40(\mathrm{M})$ & 2 & $4(8 / 2)$ & $4(8 / 2)$ & 0.0625 & $2(0.125 / 0.0625)$ & $2(0.125 / 0.0625)$ \\
\hline ATCC14018 & $0.97 \pm 0.13(\mathrm{M})$ & $2.32 \pm 0.19(\mathrm{M})$ & 16 & $4(64 / 16)$ & $4(64 / 16)$ & 0.0625 & $16(1 / 0.0625)$ & 512 (32/0.0625) \\
\hline
\end{tabular}

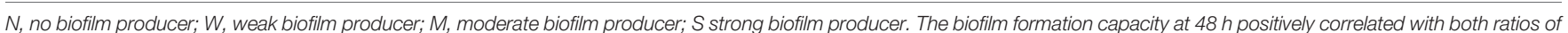

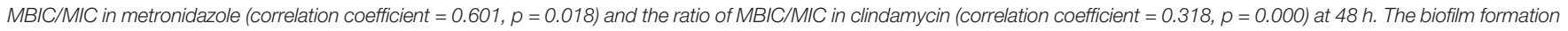

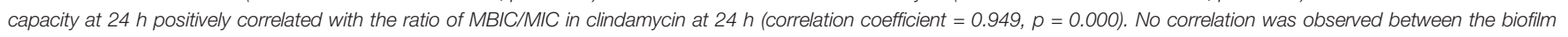
formation capacity at $24 \mathrm{~h}$ and the ratio of MBIC/MIC in metronidazole at $24 \mathrm{~h}$ (correlation coefficient $=0.350, p>0.05$ ). 
1) to interfere at the different stages of biofilm formation in Gardnerella species.

\section{Changes in Biofilm When Lactobacillus Compete and Interfere at Different Stages of Biofilm Formation of ATCC14018}

As presented in Table 2 and Figure 1, when L. rhamnosus was added to the biofilm samples formed by ATCC14018 at 0, 24, and $48 \mathrm{~h}$ (Figures 1B, E, H), the biofilm formation was significantly inhibited, with a percentage inhibition of $38.17 \% \pm$ $1.35 \%, 32.66 \% \pm 1.99 \%$, and $29.43 \% \pm 2.68 \%$, respectively, and their $p$ values were all 0.000 . The interference effect of L. rhamnosus on the biofilm formed at $0 \mathrm{~h}$ of Gardnerella species was the strongest, with a significant difference, compared with the percentage reduction of biofilm formed at 24 and $48 \mathrm{~h}$ (both $p$ values were 0.000 ).

When $L$. case $i$ was added to the samples of biofilm formed by Gardnerella species at 0, 24, and $48 \mathrm{~h}$ (Figures 1C, F, I), the biofilm thickness decreased, and the percentage reductions in biofilm formation were $10.88 \% \pm 1.85 \%, 12.57 \% \pm 0.74 \%$, and $0.57 \% \pm 1.55 \%$, respectively. The $p$ values were $0.000,0.000$, and 0.287 , respectively. $L$. casei had little effect on biofilm formation after $48 \mathrm{~h}$. The thickness reduction of biofilm formed at $48 \mathrm{~h}$ by
L. casei was significantly different from that of biofilm formed at 0 or $24 \mathrm{~h}$, and both $p$ values were 0.000 .

\section{The Changes in Quantification of ATCC14018 When Lactobacillus Compete and Interfere}

A stand curve was established with $y=-3.1036 \mathrm{X}+35.048$ from the serially diluted DNA copies in relation to $\mathrm{Ct}$ values. The linear regression slope was determined to be -3.1036 with a correlation coefficient $\left(\mathrm{R}^{2}\right)$ of 0.999 (Supplementary Figure 3). The DNA concentration range from $10^{8}$ to $10^{2}$ copies $/ \mathrm{ml}$. The dissolution and amplification curves are illustrated in Supplementary Figure 2. The specificity of primers for detecting bacteria via PCR are illustrated in Supplementary Figure 3.

As summarized in Table 2 , in the competitive assays, the quantities of Gardnerella species in samples A, B, C were $7.26 \pm$ $0.1,5.82 \pm 0.13$, and $6.78 \pm 0.05$ copies $/ \mathrm{ml}$, respectively. Lactobacillus addition at this stage revealed the strongest inhibitory effect, and the reduction in quantities of Gardnerella species were $19.88 \% \pm 2.29 \%$ and $6.7 \% \pm 0.89 \%$, respectively. In the interference assays, when L. rhamnosus and L. casei were added after Gardnerella species biofilm formation at $24 \mathrm{~h}$, the quantities of Gardnerella species were reduced by $13.69 \% \pm$

TABLE 2 | Thickness of the biofilm, absolute quantities of Gardnerella species/Lactobacillus, and pH value after the interference of Lactobacillus at different stages of ATCC 14018 cultivation.

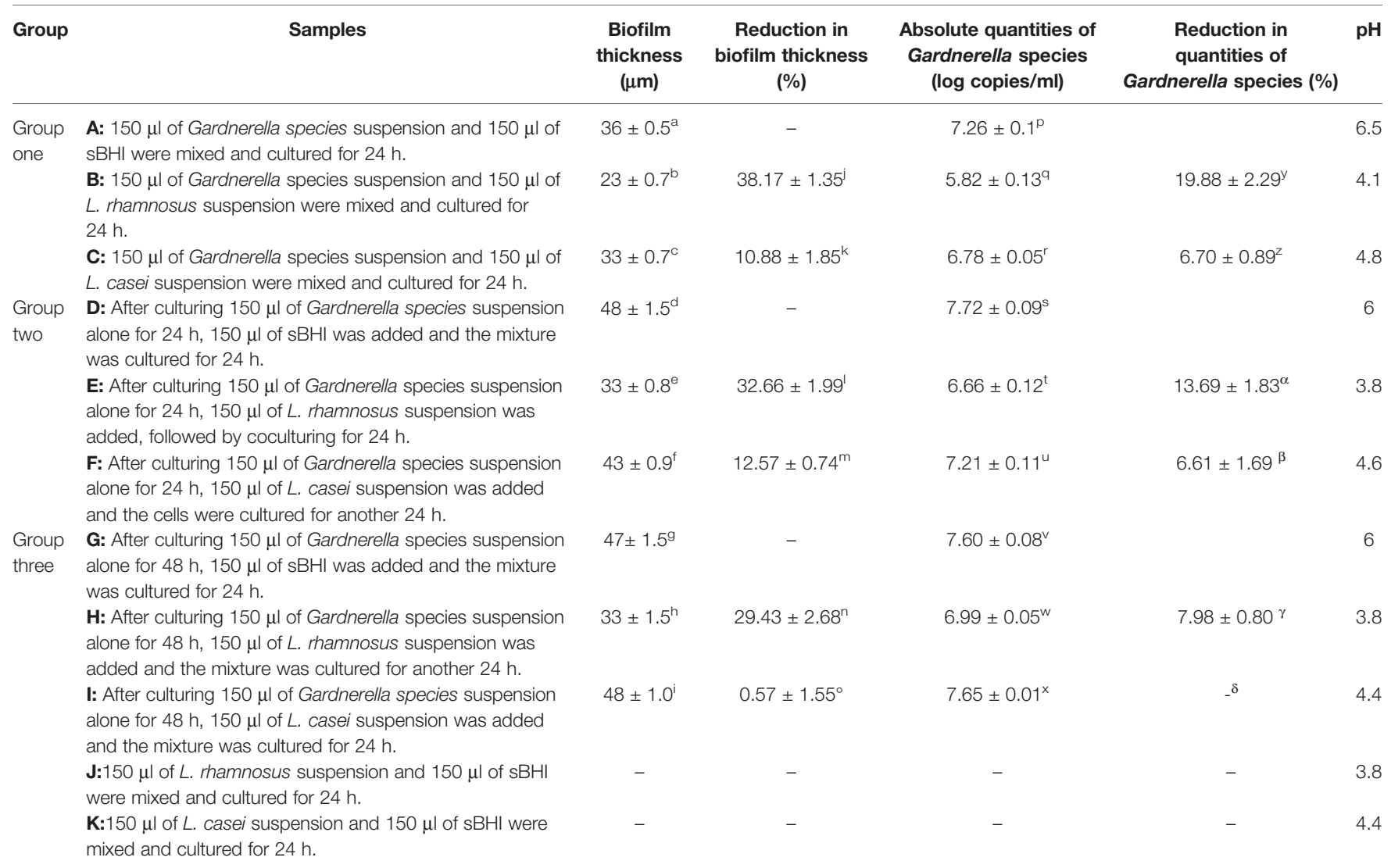

$P_{a b}=0.000 ; P_{a c}=0.000 ; P_{d e}=0.000 ; P_{d f}=0.000 ; P_{g h}=0.000 ; P_{g i}=0.287 ; P_{j l}=0.000 ; P_{j n}=0.000 ; P_{l n}=0.051 ; P_{k m}=0.091 ; P_{k o}=0.000 ; P_{m o}=0.000 ; P_{j k}=0.000 ; P_{l m}=0.000 ; P_{n o}=$ $0.000 ; P_{p q}=0.000 ; P_{p r}=0.000 ; P_{s t}=0.000 ; P_{s v}=0.000 ; P_{v w}=0.000 ; P_{v x}=0.582 ; P_{p s}=0.000 ; P_{p v}=0.001 ; P_{y \alpha}=0.000 ; P_{\alpha \gamma}=0.000 ; P_{z \gamma}=0.000 ; P_{z \beta}=0.927 ; P_{\beta \delta}=0.001 .\left(e: P_{a b}<0.05\right.$ indicates statistical significance between $a$ and $b)$. 

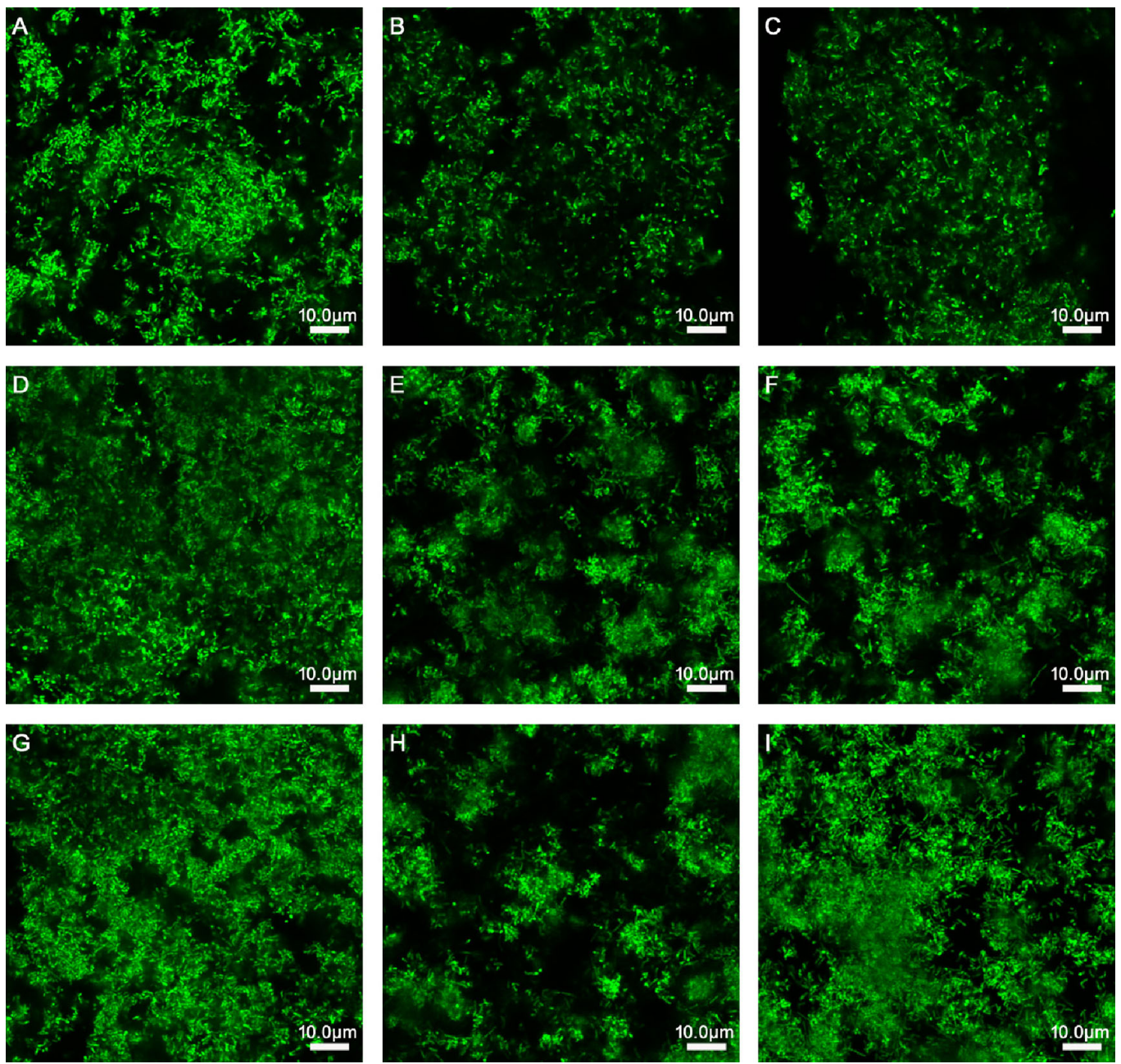

FIGURE 1 | Effects of Lactobacillus species on different stages of biofilm formation of Gardnerella species. (A) $150 \mu$ l of Gardnerella species suspension and $150 \mu$ l of supplemented brain-heart infusion (sBHI) were mixed and cultured for $24 \mathrm{~h}$. (B) $150 \mu \mathrm{l}$ of Gardnerella species suspension and $150 \mu \mathrm{l}$ of $\mathrm{L}$. rhamnosus suspension were mixed and cultured for $24 \mathrm{~h}$. (C) $150 \mu \mathrm{l}$ of Gardnerella species suspension and $150 \mu \mathrm{l}$ of $\mathrm{L}$. casei suspension were mixed and cultured for $24 \mathrm{~h}$. (D) After culturing $150 \mu \mathrm{l}$ of Gardnerella species suspension alone for $24 \mathrm{~h}, 150 \mu \mathrm{l}$ of sBHI was added and the mixture was cultured for $24 \mathrm{~h}$. (E) After culturing $150 \mu \mathrm{l}$ of Gardnerella species suspension alone for $24 \mathrm{~h}, 150 \mu \mathrm{l}$ of $\mathrm{L}$. rhamnosus suspension was added, followed by coculturing for $24 \mathrm{~h}$. (F) After culturing $150 \mu \mathrm{l}$ of Gardnerella species suspension alone for $24 \mathrm{~h}, 150 \mu \mathrm{l}$ of $\mathrm{L}$. casei suspension was added and the cells were cultured for another $24 \mathrm{~h}$. (G) After culturing $150 \mu \mathrm{l}$ of Gardnerella species suspension alone for $48 \mathrm{~h}$, $150 \mu \mathrm{l}$ of sBHI was added and the mixture was cultured for $24 \mathrm{~h}$. (H) After culturing $150 \mu \mathrm{l}$ of Gardnerella species suspension alone for $48 \mathrm{~h}, 150 \mu \mathrm{l}$ of $L$. rhamnosus suspension was added and the mixture was cultured for another $24 \mathrm{~h}$. (I) After culturing $150 \mu \mathrm{l}$ of Gardnerella species suspension alone for $48 \mathrm{~h}, 150 \mu \mathrm{l}$ of $L$. casei suspension was added and the mixture was cultured for $24 \mathrm{~h}$. The images were captured at a magnification of 63x combined with 0.75 zoom.

$1.83 \%$ and $6.61 \% \pm 1.69 \%$, respectively. When L. rhamnosus and L. case $i$ were added after Gardnerella species biofilm formation at $48 \mathrm{~h}$, the reduction in quantities of Gardnerella species was not obvious.

At the initial stages of Gardnerella species biofilm formation, Lactobacillus revealed a competitive adhesion with Gardnerella species via secretion of a bactericidal substance, the adhesion competition effect, and coaggregation (Pino et al., 2019; Barzegari et al., 2020) and presented the greatest inhibitory effect on the growth of Gardnerella species.

The inhibition of Gardnerella species biofilm by Lactobacillus during the formation or maturation phase was not as effective as that during the initial phase. This may occur because the addition of Lactobacillus had an adhesion-replacement effect on Gardnerella species, whereas Gardnerella species had adhesion and rejection effects on Lactobacillus (He et al., 2020a). Although the presence of Lactobacillus can acidify the surroundings of Gardnerella species, the biofilm enhances the tolerance of Gardnerella species to lactic acid by preventing the inhibition of physical adhesion by Lactobacillus and delaying the penetration of bactericidal substances secreted by Lactobacillus (Verstraelen and Swidsinski, 2019). We hypothesized that Gardnerella species may simultaneously release and accumulate numerous harmful substances, thereby inhibiting the growth of Lactobacillus; however, further studies are needed to confirm this hypothesis. 
The inhibitory effects of L. rhamnosus and L. casei on biofilm formation differed. Barzegari and colleagues reported that different strains of probiotics often present various antibacterial effects (Barzegari et al., 2020).

\section{Effects of Different pH on the Initial Biofilm Formation of ATCC14018}

We tracked the $\mathrm{pH}$ value in different samples after the biofilm formation of Gardnerella species was affected by lactobacilli production (see Table 2) and speculated that the acidification environment created by Lactobacillus could effectively inhibit the initial formation of Gardnerella species biofilm. Therefore, we investigated the effects of different $\mathrm{pH}$ on the initial biofilm formation of Gardnerella species.

As summarized in Table 3 and Figure 2, the results of the growth curve of the biofilm obtained via gentian violet staining assay indicated that when the $\mathrm{pH}$ was 3.5 or 7.5 , ATCC14018 could hardly form biofilms; when the $\mathrm{pH}$ was 4.0 or 7.0, Gardnerella species formed a weak biofilm; and when the $\mathrm{pH}$ ranged from 4.5 to 6.5 (particularly 5.0-6.0), strong biofilms were formed, reaching a maximum of $3.29 \pm 0.28$ (OD $595 \mathrm{~nm}$ ) at pH 5.5 and at $36 \mathrm{~h}$.

Analysis of variance for repeated measurements was used to analyze the amount of biofilm formed by Gardnerella species at different $\mathrm{pH}$ values and growth times. When different $\mathrm{pH}$ and time values were used for classification between the subjects, the results revealed significant differences in biofilm formation at different $\mathrm{pH}$ values $(p=0.000)$. Intragroup comparison revealed that time was significant for biofilm formation, which suggests that the effect of time varies from group to group.

CLSM and SEM were combined to observe the structure of the Gardnerella species biofilm at $48 \mathrm{~h}$ at different $\mathrm{pH}$. In the broth medium with a $\mathrm{pH}$ of 3.5 and 4.0, small scattered colonies were observed, and Gardnerella species could not form a mature biofilm structure (Figures 2A-D). When the broth medium had $\mathrm{pH}$ values $\geq 4.5$ and $\leq 6.5$, the biofilm was flocculent (Figures 2E-N); however, with the increase in $\mathrm{pH}$ value, the structure became more complex and clumped. When the $\mathrm{pH}$ values were 7.0 and 7.5 , the formation of biofilm gradually weakened (Figures 2O-R). The structure of the biofilm gradually became sparse and the thickness decreased at pH 7.0 (Figures 2O, P). When the $\mathrm{pH}$ value was 7.5, only scattered small aggregates and almost no biofilm formation were observed (Figures 2Q, R).

Lactic acid and other organic acids produced by Lactobacillus change the $\mathrm{pH}$ of the surrounding environment of pathogens, which may be crucial in the inhibition of pathogens (Barzegari et al., 2020). The organic acids secreted by probiotics can act as quorum sensing antagonists, which can interfere with the expression of quorum sensing-related genes and prevent biofilm formation (Lopes et al., 2017).

Although $\mathrm{pH}>6.5$ may occur in the vaginal environment due to factors such as internal ejaculation or menstrual period, $\mathrm{pH}>$ 6.5 may not last for a long time due to the self-repairing function of the vaginal environment to maintain its balance and stability. Most patients with $\mathrm{BV}$ were found to have a $\mathrm{pH}$ value in the range of 4.5-6.0 (see Supplementary Table 1, more clinical data not shown). This may be because the vagina needs to undergo a change from $\mathrm{pH}>6.5$ to the range of $3.8-4.4$ while returning to the normal $\mathrm{pH}$ range. When the $\mathrm{pH}$ is in the range of 4.5-6.0, the existing pathogenic Gardnerella species grow rapidly, and the changes in the surrounding environment promote the formation of the Gardnerella species biofilm. This may also be one of the reasons for relapse in BV patients.

Gardnerella species can hardly form biofilms when the culture medium $\mathrm{pH}$ is $<4.5$, and they have a strong biofilm formation ability when $\mathrm{pH} \geq 4.5$ and $\leq 6.5$. This confirms that acidifying the vaginal environment can reduce the biofilm production (Boskey et al., 2001). Although Gardnerella species can colonize the vagina of healthy women (Castro et al., 2015; Castro et al., 2020), several studies have found that the biofilm-forming ability of Gardnerella species from BV patients does not significantly differ from that of Gardnerella species from non-BV women under the same culture conditions (Castro et al., 2015; Castro and Cerca, 2015). This suggests that the clinical significance of the vaginal environment is important for biofilm formation. Therefore, maintaining an acidic vaginal environment and vaginal microbiota dominated by Lactobacillus are of great significance for preventing Gardnerella species infection and biofilm formation.

TABLE 3 | Effects of different pH values on the biofilm formation of ATCC 14018.

\begin{tabular}{|c|c|c|c|c|c|c|}
\hline $\mathrm{pH}$ & $\begin{array}{l}\text { OD measurement at } \\
12 \mathrm{~h} \text { (OD595nm) }\end{array}$ & $\begin{array}{l}\text { OD measurement at } \\
24 \mathrm{~h} \text { (OD595nm) }\end{array}$ & $\begin{array}{l}\text { OD measurement at } \\
36 \mathrm{~h} \text { (OD595nm) }\end{array}$ & $\begin{array}{l}\text { OD measurement at } \\
48 \mathrm{~h} \text { (OD595nm) }\end{array}$ & $\begin{array}{l}\text { OD measurement at } \\
60 \mathrm{~h} \text { (OD595nm) }\end{array}$ & $\begin{array}{c}\text { OD measurement at } \\
72 \mathrm{~h} \text { (OD595nm) }\end{array}$ \\
\hline $\begin{array}{l}\text { Blank } \\
\text { control }\end{array}$ & $0.23 \pm 0.04$ & $0.34 \pm 0.02$ & $0.38 \pm 0.08$ & $0.40 \pm 0.06$ & $0.43 \pm 0.06$ & $0.26 \pm 0.05$ \\
\hline 3.5 & $0.46 \pm 0.13(W)$ & $0.49 \pm 0.12(W)$ & $0.52 \pm 0.07(\mathrm{~N})$ & $0.47 \pm 0.04(\mathrm{~N})^{\mathrm{a}}$ & $0.54 \pm 0.06(\mathrm{~N})$ & $0.48 \pm 0.12(W)$ \\
\hline 4 & $0.57 \pm 0.12(\mathrm{~W})$ & $0.61 \pm 0.05(W)$ & $0.71 \pm 0.11(\mathrm{~W})$ & $0.67 \pm 0.13(\mathrm{~W})^{\mathrm{b}}$ & $0.72 \pm 0.08(W)$ & $0.69 \pm 0.10(W)$ \\
\hline 4.5 & $1.18 \pm 0.05(\mathrm{M})$ & $1.82 \pm 0.28(\mathrm{~S})$ & $2.03 \pm 0.29(\mathrm{~S})$ & $2.28 \pm 0.25(\mathrm{~S})^{\mathrm{c}}$ & $2.42 \pm 0.28(\mathrm{~S})$ & $2.26 \pm 0.55(\mathrm{~S})$ \\
\hline 5 & $2.41 \pm 0.28(\mathrm{~S})$ & $2.73 \pm 0.19(\mathrm{~S})$ & $2.97 \pm 0.51(\mathrm{~S})$ & $3.06 \pm 0.24(S)^{d}$ & $3.34 \pm 0.18(S)$ & $3.09 \pm 0.18(S)$ \\
\hline 5.5 & $2.69 \pm 0.26(S)$ & $2.98 \pm 0.26(S)$ & $3.29 \pm 0.28(S)$ & $3.10 \pm 0.25(S)^{e}$ & $3.16 \pm 0.21(\mathrm{~S})$ & $3.48 \pm 0.18(S)$ \\
\hline 6 & $2.19 \pm 0.21(\mathrm{~S})$ & $2.50 \pm 0.75(\mathrm{~S})$ & $2.53 \pm 0.53(\mathrm{~S})$ & $2.98 \pm 0.10(\mathrm{~S})^{f}$ & $3.07 \pm 0.14(\mathrm{~S})$ & $3.08 \pm 0.42(\mathrm{~S})$ \\
\hline 6.5 & $1.07 \pm 0.13(\mathrm{M})$ & $1.40 \pm 0.08(\mathrm{M})$ & $1.93 \pm 0.11(\mathrm{M})$ & $2.36 \pm 0.26(\mathrm{~S})^{\mathrm{g}}$ & $2.44 \pm 0.20(\mathrm{~S})$ & $2.13 \pm 0.23(\mathrm{~S})$ \\
\hline 7 & $0.77 \pm 0.13(\mathrm{M})$ & $0.69 \pm 0.10(W)$ & $0.63 \pm 0.12(\mathrm{~W})$ & $0.71 \pm 0.12(\mathrm{~W})^{\mathrm{h}}$ & $0.74 \pm 0.09(\mathrm{~W})$ & $0.55 \pm 0.09(W)$ \\
\hline 7.5 & $0.48 \pm 0.08(W)$ & $0.31 \pm 0.05(\mathrm{~N})$ & $0.39 \pm 0.07(\mathrm{~N})$ & $0.31 \pm 0.04(\mathrm{~N})^{\mathrm{i}}$ & $0.41 \pm 0.06(\mathrm{~N})$ & $0.29 \pm 0.01(\mathrm{~N})$ \\
\hline
\end{tabular}

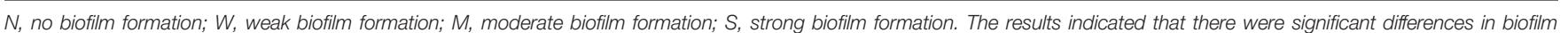

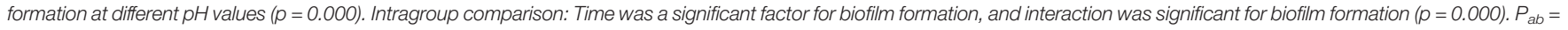
$0.203 ; P_{b c}=0.000 ; P_{c d}=0.000 ; P_{d e}=0.115 ; P_{e f}=0.049 ; P_{f g}=0.000 ; P_{g h}=0.000 ; P_{h i}=0.001$. 

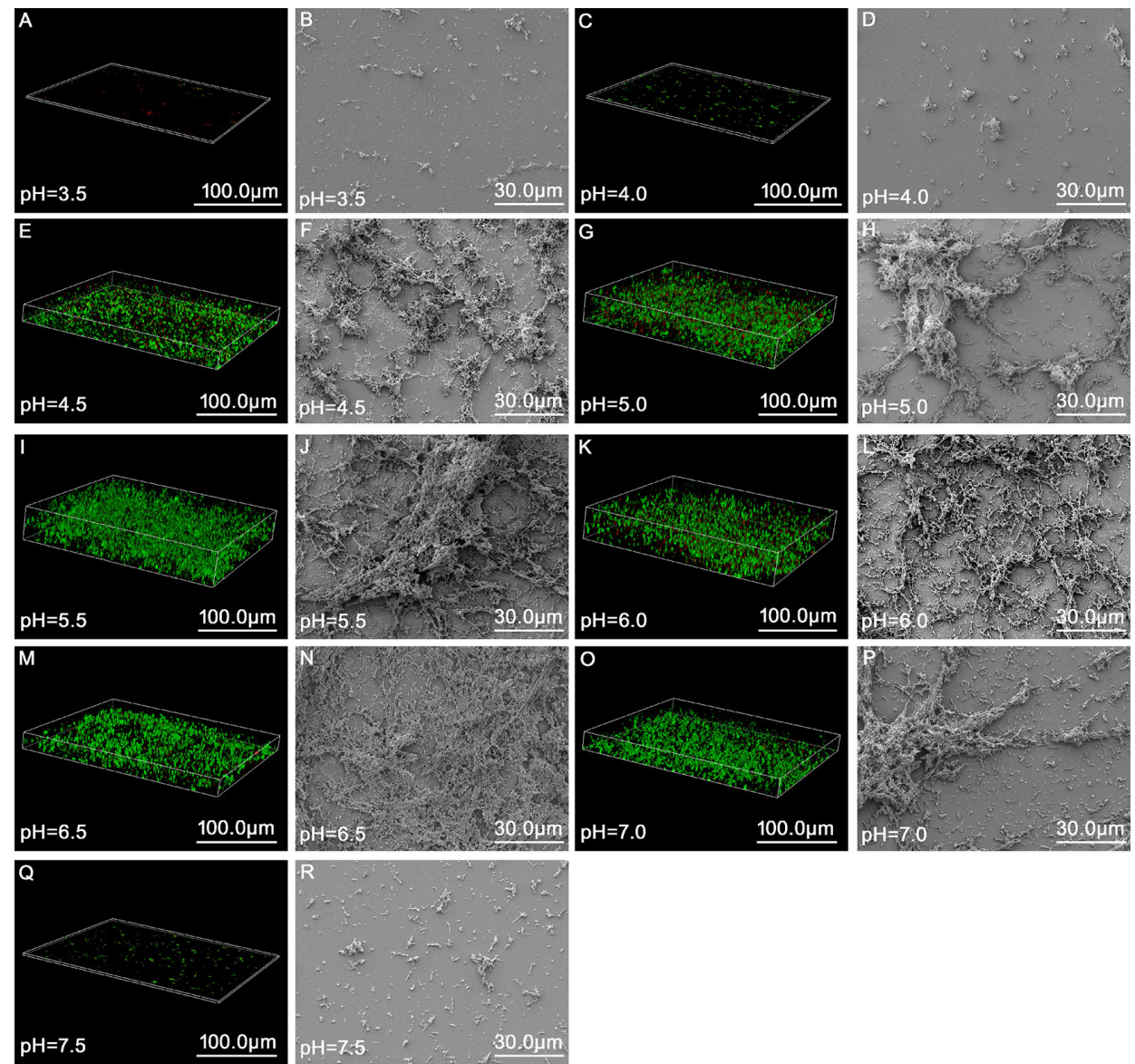

FIGURE 2 Morphology and structure of biofilms of Gardnerella species at up to $48 \mathrm{~h}$ of incubation at different pH values as observed via fluorescence microscopy and scanning electron microscopy. (A, C, E, G, I, K, M, O, Q) represent the state of biofilms observed under a fluorescence microscope (63×, zoom = 0.75 , magnification) at $\mathrm{pH} 3.5,4.0,4.5,5.0,5.5,6.0,6.5,7.0$, and 7.5 , respectively. (B, D, $\mathbf{F}, \mathbf{H}, \mathbf{J}, \mathbf{L}, \mathbf{N}, \mathbf{P}, \mathbf{R})$ refer to the structure of biofilms observed via scanning electron microscopy (1,000x magnification) at pH 3.5, 4.0, 4.5, 5.0, 5.5, 6.0, 6.5, 7.0, 7.5, respectively.

\section{CONCLUSION}

This study confirms that biofilms can increase the resistance of Gardnerella species to antibiotics. Lactobacillus added during the initial stage of Gardnerella species biofilm formation revealed the best inhibitory effect. The acidic environment with $\mathrm{pH}<4.5$ created by Lactobacillus plays an important role in the formation of Gardnerella species biofilm at the initial stage. This finding is highly significant in the treatment and prevention of biofilmrelated infections. While the evaluation of the biofilm formation capacity of Gardnerella species requires further improvement, the mechanism of inhibitory effect of Lactobacillus on Gardnerella species' biofilm remains to be further explored.

\section{DATA AVAILABILITY STATEMENT}

The original contributions presented in the study are included in the article/Supplementary Material. Further inquiries can be directed to the corresponding authors.

\section{ETHICS STATEMENT}

The studies involving human participants were reviewed and approved by The Ethics Committee of Peking University First Hospital (V2.0/201504.20), and written informed consent was obtained from all participants. The patients/participants provided their written informed consent to participate in this study.

\section{AUTHOR CONTRIBUTIONS}

$\mathrm{YH}, \mathrm{RN}, \mathrm{XN}, \mathrm{BX}$, and $\mathrm{HY}$ conceived the study design. $\mathrm{XN}$ and $\mathrm{RN}$ were responsible for the recruitment of volunteers and collection of samples. $\mathrm{YH}, \mathrm{RN}$, and $\mathrm{XN}$ performed the laboratory assays. $\mathrm{YH}$ performed the data analysis, and $\mathrm{YH}$ wrote the initial manuscript. $\mathrm{BX}$ and $\mathrm{HY}$ revised the manuscript. All authors contributed to the article and approved the submitted version. 


\section{FUNDING}

This work was supported by the National Natural Science Foundation of China (no. 81971342 and no. 81200411).

\section{ACKNOWLEDGMENTS}

We would like to thank all the participants for their support and cooperation. We would also like to thank all the researchers,

\section{REFERENCES}

Abbai, N. S., Reddy, T., and Ramjee, G. (2016). Prevalent bacterial vaginosis infection - a risk factor for incident sexually transmitted infections in women in Durban, South Africa. Int. J. STD AIDS 27 (14), 1283-1288. doi: 10.1177/ 0956462415616038

Alves, P., Castro, J., Sousa, C., Cereija, T. B., and Cerca, N. (2014). Gardnerella vaginalis Outcompetes 29 Other Bacterial Species Isolated From Patients With Bacterial Vaginosis, Using in an In Vitro Biofilm Formation Model. J. Infect. Dis. 210 (4), 593-596. doi: 10.1093/infdis/jiu131

Barzegari, A., Kheyrolahzadeh, K., Hosseiniyan Khatibi, S. M., Sharifi, S., Memar, M. Y., and Zununi Vahed, S. (2020). The Battle of Probiotics and Their Derivatives Against Biofilms. Infect. Drug Resist. 13, 659-672. doi: 10.2147/ IDR.S232982

Beaudoin, T., Yau, Y. C. W., Stapleton, P. J., Gong, Y., Wang, P. W., Guttman, D. S., et al. (2017). Staphylococcus aureus interaction with Pseudomonas aeruginosa biofilm enhances tobramycin resistance. NPJ Biofilms Microbiomes 3, 25. doi: 10.1038/s41522-017-0035-0

Bohr, L. L., Mortimer, T. D., and Pepperell, C. S. (2020). Lateral Gene Transfer Shapes Diversity of Gardnerella spp. Front. Cell Infect. Microbiol. 10:293. doi: $10.3389 /$ fcimb.2020.00293

Boskey, E. R., Cone, R. A., Whaley, K. J., and Moench, T. R. (2001). Origins of vaginal acidity: high $\mathrm{D} / \mathrm{L}$ lactate ratio is consistent with bacteria being the primary source. Hum. Reprod. 16 (9), 1809-1813. doi: 10.1093/humrep/ 16.9.1809

Breshears, L. M., Edwards, V. L., Ravel, J., and Peterson, M. L. (2015). Lactobacillus crispatus inhibits growth of Gardnerella vaginalis and Neisseria gonorrhoeae on a porcine vaginal mucosa model. BMC Microbiol. 15, 276. doi: 10.1186/ s12866-015-0608-0

Byun, R., Nadkarni, M. A., Chhour, K. L., Martin, F. E., Jacques, N. A., and Hunter, N. (2004). Quantitative analysis of diverse Lactobacillus species present in advanced dental caries. J. Clin. Microbiol. 42 (7), 3128-3136. doi: 10.1128/ JCM.42.7.3128-3136.2004

Castro, J., and Cerca, N. (2015). BV and non-BV associated Gardnerella vaginalis establish similar synergistic interactions with other BV-associated microorganisms in dual-species biofilms. Anaerobe 36, 56-59. doi: 10.1016/ j.anaerobe.2015.10.008

Castro, J., Alves, P., Sousa, C., Cereija, T., Franca, A., Jefferson, K. K., et al. (2015). Using an in-vitro biofilm model to assess the virulence potential of bacterial vaginosis or non-bacterial vaginosis Gardnerella vaginalis isolates. Sci. Rep. 5, 11640. doi: $10.1038 /$ srep 11640

Castro, J., Machado, D., and Cerca, N. (2019). Unveiling the role of Gardnerella vaginalis in polymicrobial Bacterial Vaginosis biofilms: the impact of other vaginal pathogens living as neighbors. Isme J. 13 (5), 1306-1317. doi: 10.1038/ s41396-018-0337-0

Castro, J., Jefferson, K. K., and Cerca, N. (2020). Genetic Heterogeneity and Taxonomic Diversity among Gardnerella Species. Trends Microbiol. 28 (3), 202-211. doi: 10.1016/j.tim.2019.10.002

Cerca, N., Martins, S., Cerca, F., Jefferson, K. K., Pier, G. B., Oliveira, R., et al. (2005). Comparative assessment of antibiotic susceptibility of coagulasenegative staphylococci in biofilm versus planktonic culture as assessed by bacterial enumeration or rapid XTT colorimetry. J. Antimicrob. Chemother. 56 (2), 331-336. doi: 10.1093/jac/dki217 clinicians, and technicians involved in our study for their participation and technical support.

\section{SUPPLEMENTARY MATERIAL}

The Supplementary Material for this article can be found online at: https://www.frontiersin.org/articles/10.3389/fcimb.2021. 568178/full\#supplementary-material

Chervinets, Y., Chervinets, V., Shenderov, B., Belyaeva, E., Troshin, A., Lebedev, S., et al. (2018). Adaptation and Probiotic Potential of Lactobacilli, Isolated from the Oral Cavity and Intestines of Healthy People. Probiotics Antimicrob. Proteins 10 (1), 22-33. doi: 10.1007/s12602-017-9348-9

Danielsson, D., Teigen, P. K., and Moi, H. (2011). The genital econiche: focus on microbiota and bacterial vaginosis. Ann. N. Y. Acad. Sci. 1230, 48-58. doi: 10.1111/j.1749-6632.2011.06041.x

Fux, C. A., Costerton, J. W., Stewart, P. S., and Stoodley, P. (2005). Survival strategies of infectious biofilms. Trends Microbiol. 13 (1), 34-40. doi: 10.1016/ j.tim.2004.11.010

Haddad, L. B., Wall, K. M., Kilembe, W., Vwalika, B., Khu, N. H., Brill, I., et al. (2018). Bacterial vaginosis modifies the association between hormonal contraception and HIV acquisition. AIDS 32 (5), 595-604. doi: 10.1097/ QAD.0000000000001741

Hardy, L., Cerca, N., Jespers, V., Vaneechoutte, M., and Crucitti, T. (2017). Bacterial biofilms in the vagina. Res. Microbiol. 168 (9-10), 865-874. doi: 10.1016/j.resmic.2017.02.001

Harwich, M. D.Jr., Alves, J. M., Buck, G. A., Strauss, J.F.III, Patterson, J. L., Oki, A. T., et al. (2010). Drawing the line between commensal and pathogenic Gardnerella vaginalis through genome analysis and virulence studies. BMC Genomics 11, 112. doi: 10.1186/1471-2164-11-375

He, Y., Niu, X., Wang, B., Na, R., Xiao, B., and Yang, H. (2020a). Evaluation of the Inhibitory Effects of Lactobacillus gasseri and Lactobacillus crispatus on the Adhesion of Seven Common Lower Genital Tract Infection-Causing Pathogens to Vaginal Epithelial Cells. Front. Med. 7, 1-8. doi: 10.3389/ fmed.2020.00284

He, Y., Ruan, G., Hao, H., Xue, F., Zhu, S., Xiao, B., et al. (2020b). Evaluation of Quadruple Real-Time PCR Method to Detect Enterococci Carrying Vancomycin-Resistant Genes vanA, vanB, vanM in Rectal Swabs. Front. Med. 7, 1-7. doi: 10.3389/fmed.2020.00403

Javed, A., Parvaiz, F., and Manzoor, S. (2019). Bacterial vaginosis: An insight into the prevalence, alternative treatments regimen and it's associated resistance patterns. Microb. Pathog. 127, 21-30. doi: 10.1016/j.micpath.2018.11.046

Jefferson, K. K., Goldmann, D. A., and Pier, G. B. (2005). Use of confocal microscopy to analyze the rate of vancomycin penetration through Staphylococcus aureus biofilms. Antimicrob. Agents Chemother. 49 (6), 2467-2473. doi: 10.1128/aac.49.6.2467-2473.2005

Jung, S., Park, O. J., Kim, A. R., Ahn, K. B., Lee, D., Kum, K. Y., et al. (2019). Lipoteichoic acids of lactobacilli inhibit Enterococcus faecalis biofilm formation and disrupt the preformed biofilm. J. Microbiol. 57, 1-5. doi: 10.1007/s12275-019-8538-4

Keller, M. K., Hasslof, P., Stecksen-Blicks, C., and Twetman, S. (2011). Coaggregation and growth inhibition of probiotic lactobacilli and clinical isolates of mutans streptococci: An in vitro study. Acta Odontol. Scand. 69 (5), 263-268. doi: 10.3109/00016357.2011.554863

Kim, A. R., Ahn, K. B., Yun, C. H., Park, O. J., Perinpanayagam, H., Yoo, Y. J., et al. (2019). Lactobacillus plantarum Lipoteichoic Acid Inhibits Oral Multispecies Biofilm. J. Endod. 45 (3), 310-315. doi: 10.1016/j.joen.2018.12.007

King, C. C., Jamieson, D. J., Wiener, J., Cu-Uvin, S., Klein, R. S., Rompalo, A. M., et al. (2011). Bacterial vaginosis and the natural history of human papillomavirus. Infect. Dis. Obstet. Gynecol. 2011, 319460. doi: 10.1155/2011/ 319460

Lamret, F., Colin, M., Mongaret, C., Gangloff, S. C., and Reffuveille, F. (2020). Antibiotic Tolerance of Staphylococcus aureus Biofilm in Periprosthetic Joint 
Infections and Antibiofilm Strategies. Antibiotics (Basel) 9 (9), 1-19. doi: 10.3390/antibiotics 9090547

Lopes, E. G., Moreira, D. A., Gullon, P., Gullon, B., Cardelle-Cobas, A., and Tavaria, F. K. (2017). Topical application of probiotics in skin: adhesion, antimicrobial and antibiofilm invitro assays. J. Appl. Microbiol. 122 (2), 450461. doi: 10.1111 /jam. 13349

Lv, R., Wang, K., Feng, J., Heeney, D. D., Liu, D., and Lu, X. (2019). Detection and Quantification of Viable but Non-culturable Campylobacter jejuni. Front. Microbiol. 10, 2920. doi: 10.3389/fmicb.2019.02920

Machado, A., Jefferson, K. K., and Cerca, N. (2013). Interactions between Lactobacillus crispatus and bacterial vaginosis (BV)-associated bacterial species in initial attachment and biofilm formation. Int. J. Mol. Sci. 14 (6), 12004-12012. doi: 10.3390/ijms140612004

Merghni, A., Dallel, I., Noumi, E., Kadmi, Y., Hentati, H., Tobji, S., et al. (2017). Antioxidant and antiproliferative potential of biosurfactants isolated from Lactobacillus casei and their anti-biofilm effect in oral Staphylococcus aureus strains. Microb. Pathog. 104, 84-89. doi: 10.1016/j.micpath.2017.01.017

Moragianni, D., Dryllis, G., Andromidas, P., Kapeta-Korkouli, R., Kouskouni, E., Pessach, I., et al. (2019). Genital tract infection and associated factors affect the reproductive outcome in fertile females and females undergoing in vitro fertilization. Biomed. Rep. 10 (4), 231-237. doi: 10.3892/br.2019.1194

Muzny, C. A., Taylor, C. M., Swords, W. E., Tamhane, A., Chattopadhyay, D., Cerca, N., et al. (2019). An Updated Conceptual Model on the Pathogenesis of Bacterial Vaginosis. J. Infect. Dis. 220 (9), 1399-1405. doi: 10.1093/infdis/jiz342

Patterson, J. L., Stull-Lane, A., Girerd, P. H., and Jefferson, K. K. (2010). Analysis of adherence, biofilm formation and cytotoxicity suggests a greater virulence potential of Gardnerella vaginalis relative to other bacterial-vaginosisassociated anaerobes. Microbiology-Sgm 156, 392-399. doi: 10.1099/ mic. $0.034280-0$

Peebles, K., Velloza, J., Balkus, J. E., McClelland, R. S., and Barnabas, R. V. (2019). High Global Burden and Costs of Bacterial Vaginosis: A Systematic Review and Meta-Analysis. Sex. Transm. Dis. 46 (5), 304-311. doi: 10.1097/ olq.0000000000000972

Peeters, E., Nelis, H. J., and Coenye, T. (2008). Comparison of multiple methods for quantification of microbial biofilms grown in microtiter plates. J. Microbiol. Methods 72 (2), 157-165. doi: 10.1016/j.mimet.2007.11.010

Pino, A., Bartolo, E., Caggia, C., Cianci, A., and Randazzo, C. L. (2019). Detection of vaginal lactobacilli as probiotic candidates. Sci. Rep. 9 (1), 3355. doi: 10.1038/ s41598-019-40304-3

Prax, M., and Bertram, R. (2014). Metabolic aspects of bacterial persisters. Front. Cell. Infect. Microbiol. 4, 1-6. doi: 10.3389/fcimb.2014.00148

Rajalakshmi, R., and Kalaivani, S. (2016). Prevalence of asymptomatic infections in sexually transmitted diseases attendees diagnosed with bacterial vaginosis, vaginal candidiasis, and trichomoniasis. Indian J. Sex. Transm. Dis. 37 (2), 139-142. doi: 10.4103/0253-7184.192121

Reznichenko, H., Henyk, N., Maliuk, V., Khyzhnyak, T., Tynna, Y., Filipiuk, I., et al. (2020). Oral Intake of Lactobacilli Can Be Helpful in Symptomatic Bacterial Vaginosis: A Randomized Clinical Study. J. Low Genit. Tract Dis. 24, 284-289. doi: 10.1097/lgt.0000000000000518

Rosca, A. S., Castro, J., Sousa, L. G. V., and Cerca, N. (2020). Gardnerella and vaginal health: the truth is out there. FEMS Microbiol. Rev. 44 (1), 73-105. doi: 10.1093/femsre/fuz027

Rossoni, R. D., de Barros, P. P., de Alvarenga, J. A., Ribeiro, F., Velloso, M., Fuchs, B. B., et al. (2018). Antifungal activity of clinical Lactobacillus strains against Candida albicans biofilms: identification of potential probiotic candidates to prevent oral candidiasis. Biofouling 34 (2), 212-225. doi: 10.1080/ 08927014.2018.1425402

Saweri, O. P. M., Batura, N., Adawiyah, R. A., Causer, L., Pomat, W., Vallely, A., et al. (2019). Cost and cost-effectiveness of point-of-care testing and treatment for sexually transmitted and genital infections in pregnancy in low-income and middle-income countries: A systematic review protocol. BMJ Open 9 (11), 1-5. doi: 10.1136/bmjopen-2019-029945

Stepanovic, S., Vukovic, D., Dakic, I., Savic, B., and Svabic-Vlahovic, M. (2000). A modified microtiter-plate test for quantification of staphylococcal biofilm formation. J. Microbiol. Methods 40 (2), 175-179. doi: 10.1016/s0167-7012 (00)00122-6

Stepanovic, S., Vukovic, D., Hola, V., Di Bonaventura, G., Djukic, S., Cirkovic, I., et al. (2007). Quantification of biofilm in microtiter plates: overview of testing conditions and practical recommendations for assessment of biofilm production by staphylococci. Apmis 115 (8), 891-899. doi: 10.1111/j.16000463.2007.apm_630.x

Subtil, D., Brabant, G., Tilloy, E., Devos, P., Canis, F., Fruchart, A., et al. (2018). Early clindamycin for bacterial vaginosis in pregnancy (PREMEVA): a multicentre, double-blind, randomised controlled trial. Lancet 392 (10160), 2171-2179. doi: 10.1016/s0140-6736(18)31617-9

Swidsinski, A., Mendling, W., Loening-Baucke, V., Ladhoff, A., Swidsinski, S., Hale, L. P., et al. (2005). Adherent biofilms in bacterial vaginosis. Obstet. Gynecol. 106 (5), 1013-1023. doi: 10.1097/01.AOG.0000183594.45524.d2

Swidsinski, A., Mendling, W., Loening-Baucke, V., Swidsinski, S., Doerffel, Y., Scholze, J., et al. (2008). An adherent Gardnerella vaginalis biofilm persists on the vaginal epithelium after standard therapy with oral metronidazole. Am. J. Obstet. Gynecol. 198 (1), 1-6. doi: 10.1016/j.ajog.2007.06.039

Swidsinski, A., Doerffel, Y., Loening-Baucke, V., Swidsinski, S., Verstraelen, H., Vaneechoutte, M., et al. (2010). Gardnerella Biofilm Involves Females and Males and Is Transmitted Sexually. Gynecol. Obstet. Invest. 70 (4), 256-263. doi: $10.1159 / 000314015$

Swidsinski, A., Doerffel, Y., Loening-Baucke, V., Schilling, J., and Mendling, W. (2011). Response of Gardnerella vaginalis biofilm to 5 days of moxifloxacin treatment. FEMS Immunol. Med. Microbiol. 61 (1), 41-46. doi: 10.1111/j.1574695X.2010.00743.X

Tan, Y., Leonhard, M., Moser, D., Ma, S., and Schneider-Stickler, B. (2018). Inhibitory effect of probiotic lactobacilli supernatants on single and mixed non-albicans Candida species biofilm. Arch. Oral. Biol. 85, 40-45. doi: 10.1016/ j.archoralbio.2017.10.002

Thellin, O., Zorzi, W., Zorzi, D., Delvenne, P., Heinen, E., ElMoualij, B., et al. (2016). Lysozyme as a cotreatment during antibiotics use against vaginal infections: An in vitro study on Gardnerella vaginalis biofilm models. Int. Microbiol. 19 (2), 101-107. doi: 10.2436/20.1501.01.268

Thieme, L., Hartung, A., Tramm, K., Klinger-Strobel, M., Jandt, K. D., Makarewicz, O., et al. (2019). MBEC Versus MBIC: the Lack of Differentiation between Biofilm Reducing and Inhibitory Effects as a Current Problem in Biofilm Methodology. Biol. Proced. Online 21, 18. doi: 10.1186/ s12575-019-0106-0

Turovskiy, Y., Cheryian, T., Algburi, A., Wirawan, R. E., Takhistov, P., Sinko, P. J., et al. (2012). Susceptibility of Gardnerella vaginalis biofilms to natural antimicrobials subtilosin, epsilon-poly-L-lysine, and lauramide arginine ethyl ester. Infect. Dis. Obstet. Gynecol. 2012, 284762. doi: 10.1155/2012/284762

Van Acker, H., Van Dijck, P., and Coenye, T. (2014). Molecular mechanisms of antimicrobial tolerance and resistance in bacterial and fungal biofilms. Trends Microbiol. 22 (6), 326-333. doi: 10.1016/j.tim.2014.02.001

Vaneechoutte, M., Guschin, A., Van Simaey, L., Gansemans, Y., Van Nieuwerburgh, F., and Cools, P. (2019). Emended description of Gardnerella vaginalis and description of Gardnerella leopoldii sp. nov., Gardnerella piotii sp. nov. and Gardnerella swidsinskii sp. nov., with delineation of 13 genomic species within the genus Gardnerella. Int. J. Syst. Evol. Microbiol. 69 (3), 679687. doi: $10.1099 /$ ijsem.0.003200

Verstraelen, H., and Swidsinski, A. (2019). The biofilm in bacterial vaginosis: implications for epidemiology, diagnosis and treatment: 2018 update. Curr. Opin. Infect. Dis. 32 (1), 38-42. doi: 10.1097/QCO.0000000000000516

Verwijs, M. C., Agaba, S. K., Darby, A. C., and van de Wijgert, J. (2020). Impact of oral metronidazole treatment on the vaginal microbiota and correlates of treatment failure. Am. J. Obstet. Gynecol. 222 (2), 157.e151-157.e113. doi: 10.1016/j.ajog.2019.08.008

Wayne, PA, USA (2018). Clinical and Laboratory Standards Institute, Standards for Antimicrobial Susceptibility Testing (Wayne, PA, USA: Clinical and Laboratory Standards Institute), M100-MS26.

Xiao, B., Niu, X., Han, N., Wang, B., Du, P., Na, R., et al. (2016). Predictive value of the composition of the vaginal microbiota in bacterial vaginosis, a dynamic study to identify recurrence-related flora. Sci. Rep. 6, 26674. doi: 10.1038/ srep26674

Xiao, B., Wu, C., Song, W., Niu, X., Qin, N., Liu, Z., et al. (2019). Association Analysis on Recurrence of Bacterial Vaginosis Revealed Microbes and Clinical Variables Important for Treatment Outcome. Front. Cell Infect. Microbiol. 9, 189. doi: $10.3389 /$ fcimb.2019.00189

Yang, S., Reid, G., Challis, J. R. G., Gloor, G. B., Asztalos, E., Money, D., et al. (2020). Effect of Oral Probiotic Lactobacillus rhamnosus GR-1 and 
Lactobacillus reuteri RC-14 on the Vaginal Microbiota, Cytokines and Chemokines in Pregnant Women. Nutrients 12 (2), 1-17. doi: 10.3390/ nu12020368

Conflict of Interest: The authors declare that the research was conducted in the absence of any commercial or financial relationships that could be construed as a potential conflict of interest.
Copyright (c) $2021 \mathrm{He}$, Na, Niu, Xiao and Yang. This is an open-access article distributed under the terms of the Creative Commons Attribution License (CC BY). The use, distribution or reproduction in other forums is permitted, provided the original author(s) and the copyright owner(s) are credited and that the original publication in this journal is cited, in accordance with accepted academic practice. No use, distribution or reproduction is permitted which does not comply with these terms. 